\title{
Study on Nutritional Problems in Preschool Aged Children of Kaski District of Nepal
}

\author{
$\mathrm{J}^{\text {ACHARYA*1 }}{ }^{*}$ E VAN TEIJLINGEN ${ }^{1-3}, \mathrm{~J}^{\text {MURPHY }}{ }^{1}$ AND M HIND ${ }^{1}$ \\ ${ }^{1}$ Faculty of Health \& Social Sciences, Bournemouth University, Bournemouth, UK \\ ${ }^{2}$ Visiting Professor, Manmahon Memorial Institute of Health Sciences affiliated with Tribhuwan \\ University, Nepal \\ ${ }^{3}$ Visiting Professor, Nobel College affiliated with Pokhara University, Nepal \\ *Email: jacharya@bournemouth.ac.uk
}

Received: 25 January 2015| Revised: 19 February 2015| Accepted: 4 March 2015

Published online: April 06, 2015

The Author(s) 2015. This article is published with open access at www.chitkara.edu.in/publications

\begin{abstract}
Undernutrition remains a key public health burden in Nepal. This study aimed to measure knowledge, attitudes, and beliefs about nutritious food amongst mothers of $3-5$ year olds from rural and urban areas. A cross-sectional mixed-methods approach comprised a quantitative survey and qualitative focus groups. The community-based survey included 524 mothers of children who are no longer breastfed. Open-ended and structured questions investigated knowledge, beliefs and attitudes about nutritious food, child feeding patterns, and major barriers, food insecurity, and health seeking behaviours. Focus groups were held with key informants, a thematic analysis was applied to the qualitative data.

Results: Major barriers to recommending nutritious foods included: lack of knowledge (19\%); cost (21\%); and culture/beliefs (7\%). Nearly 55\% children were given fruit once a week. Almost $37 \%$ of mothers never gave meat, fish and egg regularly to their children and $34 \%$ did not choose healthy food from stores, and $12 \%$ lacked food. Most children (57\%) had been taken at least once to a spiritual healer and $16 \%$ had been taken more than once. The qualitative analysis suggested that important factors of knowledge, attitudes, and beliefs about healthy diet are poverty, education, strong cultural beliefs, family size, household income, time and a growing preference for fast food.

Conclusion: Knowledge of and attitudes towards nutritious food is still poor. Beliefs about food practice are strongly embedded in Nepal. Thus, this study shows that policymakers should consider a public health intervention and approach based around changing these largely cultural beliefs and behaviours.
\end{abstract}

Keywords: Malnutrition; Knowledge, attitudes and beliefs about nutritious food; poverty; health

\section{BACKGROUND}

Undernutrition at an early age leads to a drop in mental and physical growth during childhood and disturbs school performance and decreases earning potential in a later life Christakis [19], [23]. Nepal has some of the highest undernutrition rates in the world. For example, $11 \%$ of under-fives are wasted, $29 \%$ are underweight and $41 \%$ are stunted. However, these issues are often exacerbated in remote hill and mountainous regions, where stunting is above $60 \%$ [44].

Journal of Multidisciplinary Research in Healthcare

Vol. 1, No. 2 April 2015 pp. $97-118$ 
Acharya, $\mathrm{J}$ van Teijlingen, $\mathrm{E}$ Murphy, J Hind, $\mathrm{M}$
The GDP (gross domestic product) per person in Nepal (US $\$ 1,049 \mathrm{p} / \mathrm{a}$ ) is very low [77] . Farm production does not keep up with population growth. On this basis, 33 districts out of 75 have food deficits and 4.5 million Nepalese citizens are undernourished. WFP (the World Food Programme) stated that most of the households, who live below the poverty line, have squeezed the amount of meal and stay without eating during farm lean epoch. WFP estimated that nearly $70 \%$ of children are poorly fed in Nepal. Thus the children of Nepal experience physical and mental effects including stunting, which means they face lifelong ill health and relative to other nations are less productive [71]. Many child deaths result from undernutrition, estimated to be associated with over half of total childhood deaths in developing countries, can be attributed to just mild and moderate undernutrition, varying from $45 \%$ for deaths due to measles to $61 \%$ for deaths due to diarrhoea [19]. Most studies on child nutritional status have focused on prevalence of undernutrition among under-five children and socioeconomic, demographic and cultural factors associated with child undernutrition in Nepal [34].

\section{Global scenario of poor nutrition and underlying cause}

Malnutrition refers to deficiencies of micronutrients, undernutrition, overweight and obesity. Malnutrition not only affects people's health and wellbeing, it also people physical and mental growth, suppressing body immune system, increasing risk of noninfectious and transmissible diseases, reducing productivity and other negative social and economic consequences on individuals, households, societies and nations [36].

In this paper we use malnutrition to mean undernutrition. In that sense over the past decade, many nations have managed to decrease the burden of undernutrition. According to joint assessment programme of UNICEF, WHO and World Bank, 805 million people are affected from hunger in 2012 and 2014, nearly 161 million children who are under five years of age, suffering from stunting (chronic malnutrition), and wasting (acute malnutrition) affects 51 million children of under five years age of children [66]. While, undernutrtion was the major underlying cause of under five children in global which accounts $45 \%$ of total deaths in the global in 2013. FAO, claimed that the dietary risk factors with inadequate physical activity responsible for nearly $10 \%$ of disability and ailment of the global burden.

Thus the nutritional status of a locality, groups of the region of country indicates the socio-economic status of the population [17]. Nutritional status is expressed as one being normal, underweight, stunted, wasted, over weight and micronutrient deficit. Nutritional status is linked to the availability of healthy food, income sources, local food production is good, and getting nutrition awareness good environment, enough dietary intake including healthy feeding pattern, proper utilization of food, which depends on physiological status of the body, which in turn, is influenced by the environmental situation, accessibility to safe water, and the morbidity status that is the result of inadequacies in these situations [76]. Nutritional status is result 
of a multifaceted inter-relationship between environmental and social factors and the individual in a community. Key determinants (availability, affordability, and accessibility, purchasing power of people, dietary intake, education, agriculture, and healthy environment) are also important to address this problem [64]. It is only possible to tackle the problem of nutrition from the community by implementing comprehensive nutrition programmes (curative, preventive and promotive). This study focused on undernutrition of children aged 3-5 (as reported by their mothers) and correlates this with determinants.

\section{Literature review}

Malnutrition remains one of the most common causes of morbidity and mortality among children under five children throughout the World [67]. Internationally, more than 10 million under five children die every year from avoidable illnesses despite effective health interventions and half of the deaths are due to malnutrition. Generally malnourished children have poor immunity power to infection which is more like to die. They are more vulnerable with weak health [15]. Undernutrition is very high in South Asia even compared to Africa [20].

In Sub-Saharan Africa chronic undernutrition has been a problem for young children. More children of these who fail to reach the normal international standard height for age. Similarly, between 1990 and 2006 child stunting in Southeast Asia has dropped to $42 \%$ from $52 \%$. Nigerian rural community study revealed that wasting, underweight and stunting prevalence rates were $9 \%, 23.1 \%$, and $26.7 \%$ respectively. This study carried out on influence of socio-economic determinants on nutritional status of children [7], [57]. Similar study at Bangladesh found high prevalence rate of underweight (40\%) and stunting (42\%) in under five children [58] . The research in Mongolia and Dhankuta of Nepal also found high prevalence rates of undernutrition which were $15.6 \%$ stunting, $1.7 \%$ wasting and $4.7 \%$ underweight and $27 \%$ stunting, $37 \%$ wasting and $11 \%$ underweight respectively [50],[56] . One study conducted in preschool aged children of rural part of western Kenya found that prevalence of wasting $4 \%$, stunting $30 \%$ and underweight $20 \%$ respectively [33].

In the context of developing world, the major factors of undernutrition multifaceted and interlinked and include: low diet and infections, access to health facilities, food security, sanitation and healthy environment and child feeding/caring practices which are influenced by family socio-economic circumstances [42]. According to a study in Bangladesh that the BMI of mothers, pre \& postnatal visits, age of mothers, education of parents and family economic status are major factors of under-five child malnutrition [58]. In regards to association with nutrition status and socioeconomic determinates Osun state of Nigeria study (2009) showed that children of less educated mother of the area had two times the prevalence rate of stunting. Similarly children of mothers with secondary education were frequently suffered by wasting and less educated mothers but there was no any reliable association in the
Study on Nutritional Problems in Preschool Aged Children of Kaski District of Nepal 
Acharya, $\mathrm{J}$ van Teijlingen, $\mathrm{E}$ Murphy, J Hind, $\mathrm{M}$ design of stunting or wasting with education level of paternal. Higher prevalence of wasting was observed with poor income of mothers and overcrowding. Thus, no link was found with social class and source of drinking water [56] . The study was conducted in Kwara state of Nigeria, to collect information on prevalence and cause of malnutrition among under five children of famers group, found that malnutrition were significant link with child age and gender, body mass index and education level of mother, calorie consumption of the family, sanitation and hygiene such as clean drinking water and system of defecation [68]. A study conducted in Dhankuta Nepal, explored that low socio-economic status of households were high risk determinants for underweight and stunting on the other hand, children from educated and joint households were found less likely to be stunted than those in nuclear households. It has seen that caste or ethnic group and mother's age at child gestation have important link with stunting but it was not linked with education of mothers. Alike, Alrawakeeb valley of Sudan found that education of mothers of under five children to be strongest determinates associated with malnutrition [56], [49].

In regards to association with socio-economic status and malnutrition, a study conducted in rural area of Gumbrit, had found that household income was strongly associated with malnutrition [25] and Beta- Israel study also revealed that child's age, gender, history of infections (diarrhoea), length of breastfeeding, child feeding practices such as method of feeding, pre lacteal feeds, colostrum, types of diet, age of complementary food, were the major contributing factors for undernutrition [5]. Undernunutrition is strongly associated with social class, ecological, economic and many more other determinants which differ from nation to nation. Besides this most serious problems are primarily low consumption of meals, household's income, locality, education, occupation of parents, birth spacing or interval, sanitation and hygiene and source of drinking water [63],[80] . According to a study conducted in rural Tigray of Northern Ethiopia (2005), pre-lacteal feeding practice, age of child, characteristics of maternal anthropometric, insufficient complementary foods, and locality were the major contribution factors for the stunting and underweight [41].

The major significant linked determinants of poor nutrition comprises income of households, level of education, parents status in terms of nutrition, access to safe drinking water, sanitation, primary health care facility and access, child's age and gender. These contributing factors of undernunutrition may vary between communities, regions and countries and over time. Presented literature showed that factors such as child caring, knowledge of health practice, parent's education level, age of child have strong, low -birth weight of children, lack of decision making mainly on spending of money, and lack of cattle effect on family and community variables which the child develops [39],[81].

Regional assessment of United Nation's Standing Committee on Nutrition revealed that condition of stunting (32\%) and underweight (40\%) in Nepal which exceeded the average prevalence rate in South Central Asia [65. NHDS (2011) report showed 
progress on child nutritional status with underweight reduced to $29 \%$ and stunting to $41 \%$ [44]. In Nepal maternal under-nutrition is also a major alarm. The report of NDHS (2011) presented that one-fifth of women ages 15-49 have underweight (less than 18.5 BMI). However, this also has been progressing to a lesser degree. Similarly, NHDS (2011) reported that prevalence rate of anemia in children $46 \%$ and women $35 \%$ which to be a major health problem in Nepal. However, child and maternal under-nutrition is a serious concern that urgently requires targeted, effective interventions to tackle these issues [44].

\section{Scenario of nutritional problems in South Asia and Nepal}

Stunting still remains a main challenge in South Asia. This region accounts about $40 \%$ of the global burden of child stunting in the world [73]. The stunting prevalence of under five years aged children in South Asia has reduced from nearly $61 \%$ to $38 \%$ between 1990 and 2012 [66].

Nepal Demographic and Health Survey in 2011 showed that prevalence of undernutrition in Nepal was 11\% wasting, 41\% stunting and 295 underweight. It has slightly improved in stunting (49\%) and underweight (29\%) between 2006 and 2011. But the wasting (11\%) remains more or less same which declined from $13 \%$ to $11 \%$ between 2006 and 2011 . The below given bar chart illuminate clear feature

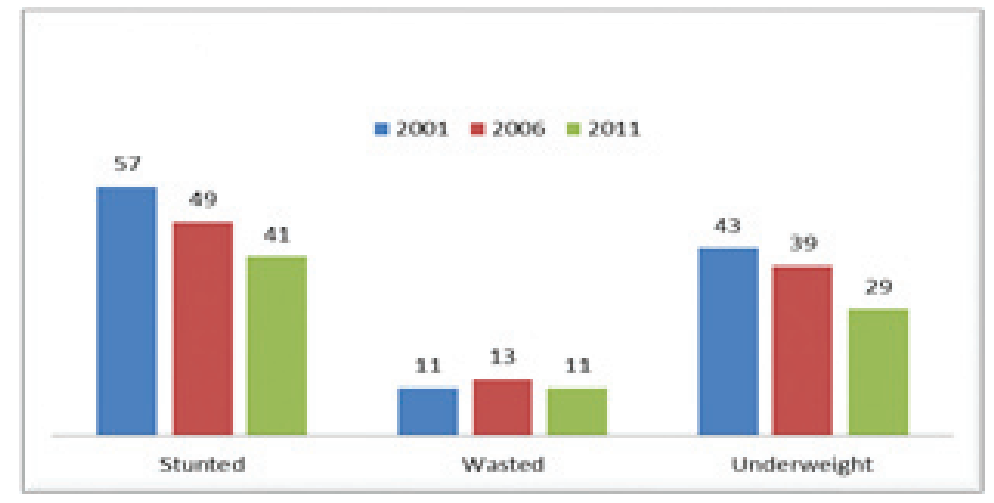

Figure 1: Nepal Demographic and Health Survey 2011

Nutritional Status of Nepal

Source: NDHS, 2011

about it. So the existing figures indicate that intervention should be focused on rural parts mainly in poorest quintile [44].

Similarly, the women aged between 15-49 years of age have a fairly overall high prevalence of anaemia (35\%), and more in rural (36\%) than in urban $(28 \%)$ parts of the country. Rural women $(36 \%)$ are more affected which compare to national
Study on Nutritional Problems in Preschool Aged Children of Kaski District of Nepal 
Acharya, J van Teijlingen, E Murphy, J Hind, M

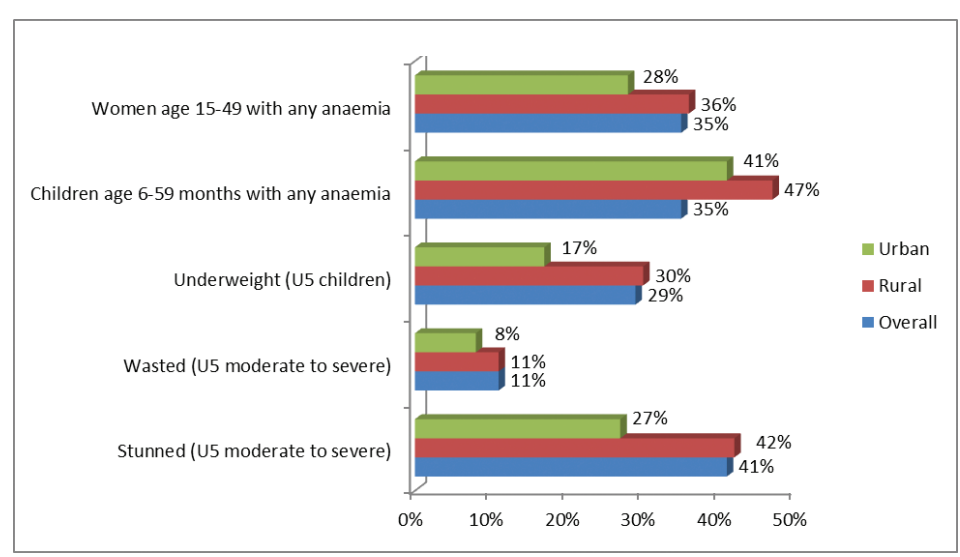

Figure 2: Nutritional problems in Nepal: Rural vs Urban (Source: NDHS 2011)

level $(35 \%)$ in prevalence of anaemia. According to below graph (graph 2), rural prevalence is equal to urban so, it indicates that public health intervention on nutrition must focus in both parts of the country [44].

\section{Aims and objectives}

To address some of the issues raised above this study aims to address two aims: First to assess the level of knowledge, attitudes and beliefs about food recommendation for preschool aged children amongst Rural/ Urban mothers; and secondly, establish major barriers amongst mothers to feeding their off-spring healthy food.The objectives are:

\section{Individual study}

- Establish the knowledge of food for children amongst rural and urban mothers.

- Find out attitudes/beliefs regarding food amongst rural and urban mothers.

- Assess health seeking behaviour for malnourished children in rural and urban communities and rationale for choices in health services to overcome on health illnesses (where they go for treatment such as health institutions (private or government), traditional/ spiritual healer, or quack)

- establish knowledge of, attitudes towards and beliefs on nutritious food of Female Community Health Volunteers (FCHV)

- Determine factors that affect availability of food (last six months), where they access good food at religious \& cultural events

- Describe the challenges that exist for mothers giving their children food and how they attempt to overcome them

- Measure the level of knowledge of and attitudes towards food-related health promotion. 


\section{Epidemiological study}

- Establish population-based problems using epidemiological data of nutritional status of preschool aged children (aged 3 to 5 years) in Kaski district.

- Identify higher risk groups for under nutrition: gender, age, caste/ethic group, wealth ranking.

- Assess health seeking behaviour for malnourished children in rural and urban communities and the rationale for choices in health access

Research Methods: Mixed methods approach with quantitative (structured interview questionnaire) and qualitative (focus group discussion).

\section{Sample size: 473}

The study focuses on mothers of children between 36-60 months old. Sample size calculated using by sample size calculation software (FluidSurveys ${ }^{\mathrm{TM}}$ ). The questionnaire survey data was collected 524.

Study Location: Pokhara and Lekhnath of Kaski district, Nepal

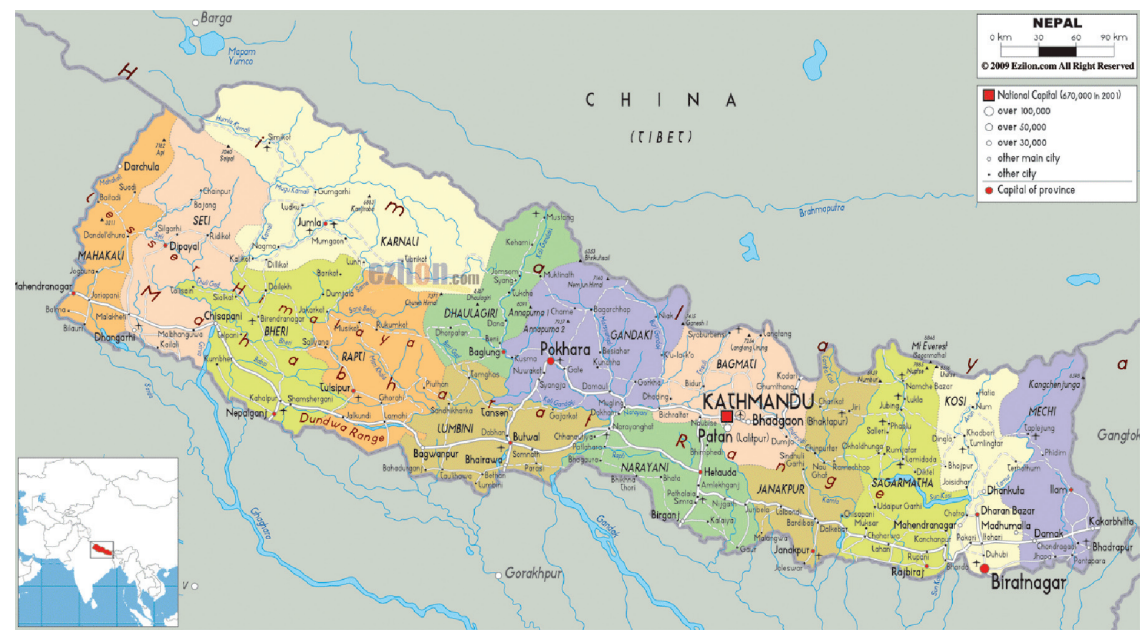

Figure 3: Map of study location

Source: ezilon maps (http://www.ezilon.com/maps/asia/nepal-maps.html)

\section{Ethical consideration}

The study received ethical approval from the Nepal Health Research Council \& Bournemouth University.
Study on Nutritional

Problems in Preschool Aged

Children of Kaski

District of Nepal

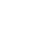


Acharya, $\mathrm{J}$ van Teijlingen, E Murphy, $\mathrm{J}$ Hind, $\mathrm{M}$

\section{Exclusion criteria}

a. 0 - 35 month old children

b. $>5$ years old children

c. Breast feeding children

\section{Rationale}

Justification Undernutrition is one of the main health problems facing children in under five age group in Nepal. The prevalence of undernutrition enforces costs on the Nepalese economy as well as society. The high mortality rate associated with poor nutrition leads to the loss of the economic prospective of the child. It harms children in several ways, predisposing children to diverse infectious diseases, psychosocial mal-development, and deficiencies on cognitive skills. The prevalence of undernutrition in Nepal is comparatively well known, but not specific to the regions, localities and residence so far and also fluctuate among districts, localities and dwelling and insufficient statics available in study area particularly public health prospectively. Previously conducted studies in other parts of the country were still lacking in addressing the public health prospectively and main associated factors of undernutrition. Therefore, this study was design to assess the associated factors mainly public health prospective among children aged 36-60 months can be used as a reference in priority setting and designing effective nutritional programmes in Kaski district of Nepal.

\section{RESULTS}

Firstly it shows demographic characteristics of both approaches: Quantitative and Qualitative. This section describes the outcomes of this study which is divided into two parts: a) Quantitative and b) Qualitative. The major results of Quantitative approach are described in figures and summary. Similarly Qualitative results are presented in words form.

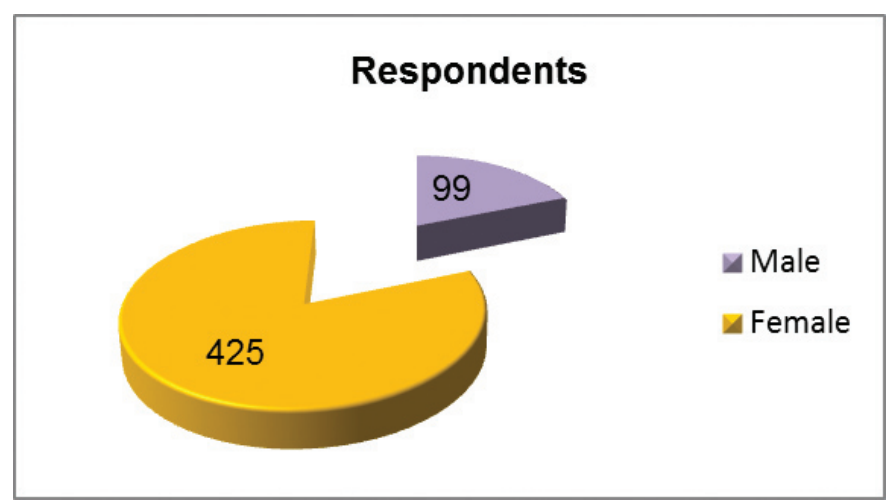

Figure 4: Gender of interview respondents 


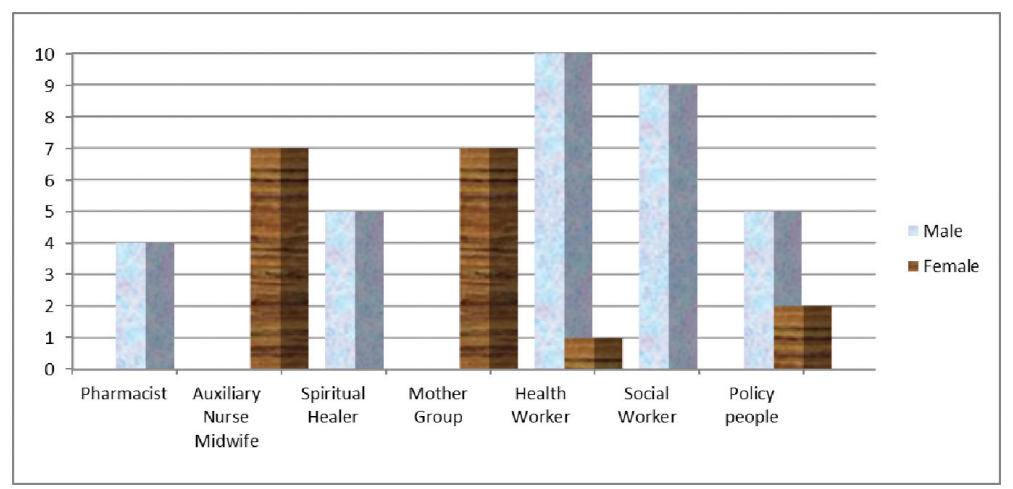

Study on Nutritional

Problems in

Preschool Aged

Children of Kaski

District of Nepal

Figure 6: Gender distribution of FGDs

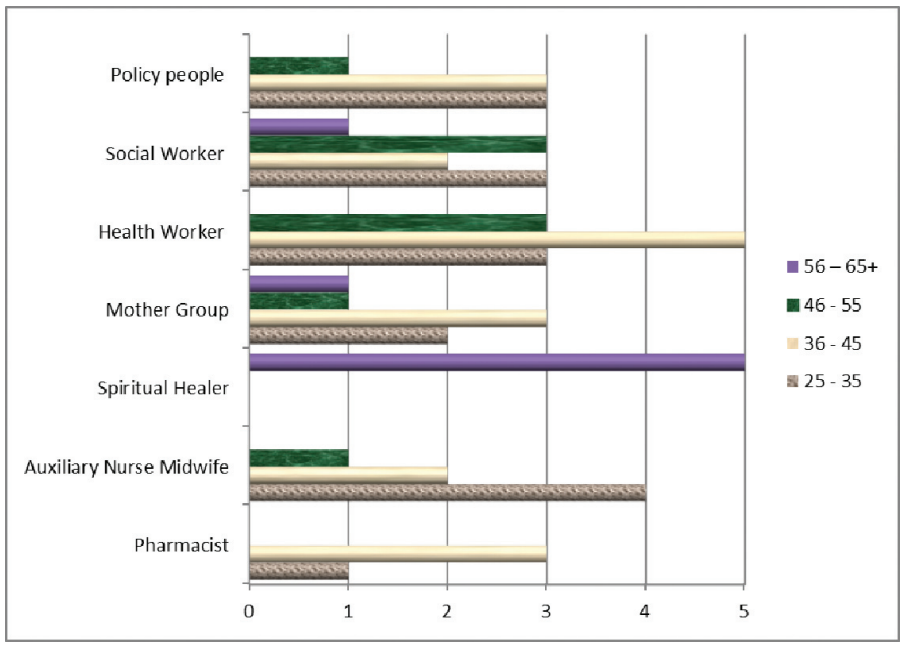

Figure 7: Distribution of age groups of FGDs

\section{a. Quantitative outcomes}
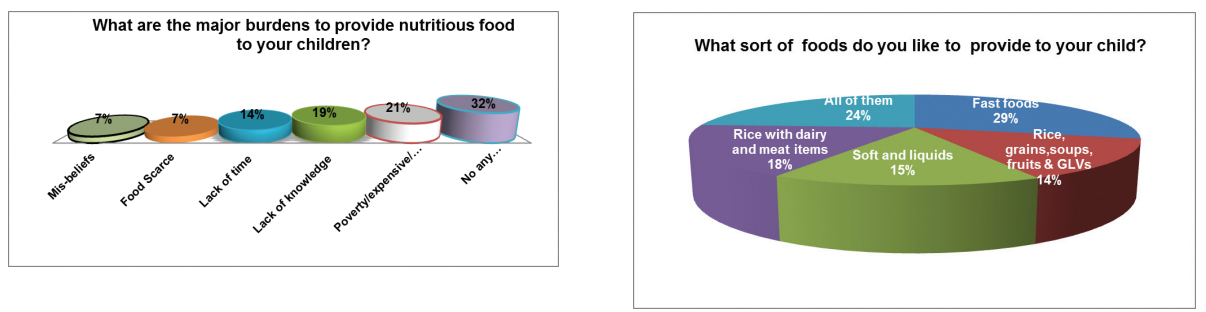

Figure 8 
Acharya, J van Teijlingen, E Murphy, J Hind, $\mathrm{M}$
- Major barriers to recommending nutritious foods included: lack of knowledge (19\%); high market prices (21\%); and cultural influences or beliefs (7\%).

- $55 \%$ children are providing fruits once in week. Similarly $29 \%$ of families never give fruits and $19 \%$ tiffin with salad to their children.

- $19 \%$ of mothers cannot choose nutritious food from the grocery store.

- About $12 \%$ respondents lacked food, 68\% in June July \& August, 13\% in December, January \& February and $9 \%$ in March, April \& May respectively.

- Nearly $57 \%$ children had been taken at least once to a spiritual healer and $16 \%$ on multiple occasions for the treatment.

- About $20 \%$ of mother believed eating green leafy vegetables and fruits during illness affect child health negatively.

- Nearly $8 \%$ respondent feed dairy product and meat items at a same time to their children but $92 \%$ do not.

- Almost 19\% mothers of the community believed that feeding of green leafy vegetables and fruits during the illness period caused harm to child and only $10 \%$ mothers have no knowledge about it.

- $11 \%$ children have fed one - two times, and $79 \%$ three - four times a day respectively. But nearly ten percent child fed nothing in last 24 hours.

- The study revealed $65 \%$ mothers, $6 \%$ father, $14 \%$ grandparents and $16 \%$ others were responsible to taking care of children respectively.

- The study found $66 \%$ mothers, $5 \%$ fathers, $18 \%$ grandparents and $11 \%$ others were responsible to feed their children

\section{b. Qualitative Outcomes}

Recognize that the root causes of and factors leading to malnutrition are complex and multidimensional:

a) Poverty, underdevelopment and low socio-economic status are major contributors to malnutrition in both rural and urban areas;

b) The lack of access at all times to sufficient food, which is adequate both in quantity and quality which conforms with the beliefs, culture, traditions, dietary habits

c) Malnutrition is often aggravated by poor infant and young child feeding and care practices, poor sanitation and hygiene, lack of access to education, quality health systems and safe drinking water, foodborne infections and parasitic infestations, ingestion of harmful levels of contaminants due to unsafe food from production to consumption;

Food behaviour and culture are strongly associated in Nepalese community. Food habits and practices are strictly linked to the wider culture. The people follows the codes of conduct in relation to food consumption, food preparation methods and eating habits, select of food, the meals taken daily, time and portion of meal eaten and size. 
Regarding the most affected ethnic groups, all groups noted that poor, illiterate and underserved populations areas vulnerable and due to poverty, poor knowledge and strongly embedded cultural beliefs and taboos.

In the context of Pokhara city, living standard is higher than other cities of Nepal. Because of Pokhara is a main tourist area in Nepal. Consumable items mainly fruits; green vegetables and other commodity are expensive. Disadvantaged and poor groups are particularly affected by high market price [16].

"I cannot buy healthy foods due to lack of money as well as high prices."

\section{FGD: Mother Group Nadipur, Pokhara}

"There is no any choices on healthy diets by low income groups because they hardly capable to afford dairy product \& meat items thus children from this groups are more vulnerable of undernutrition."

FGD: Policy People, Pokhara

In Nepal woman's status is very low and it is even more mainly in poor and disadvantaged groups [38]. They work nearly double than men in this community. In some ethnic group, they hardly get time for child care and feeding. They are responsible mainly farm and house works.

"I have no time to care of my daughter due to loads of house and office work. My daughter is being cared by my mother-in-law whose mind is completely occupied by beliefs and taboos mainly on child care and feeding."

FGD: ANM, Pokhara

"Poor people of this area are deprived of basic capabilities rather than simply a lowness of income. They are also destitute of basic needs, rights and opportunities and suffered from the natural disaster."

FGD: Policy Maker, Pokhara

Most of the women reported that they squeezed out colostrum due to cultural beliefs about colostrum and advised by mother-in-laws, spiritual healers and some point of health workers. Though it is disagreeing to the World Health Organisation recommendation that breastfeeding should start in the first hour after birth, it is important because it indicates that women were providing it to infant [74]. It is energetic in terms of stimulating mothers milk supply [52]. This may be why the practice of colostrum discarding action being done mainly in South Asian region which is not a harmful as previously thought [48].

"In my case, I could not feed colostrum to my children because my mother-in-law forced me to discard colostrum before start the breastfeeding. But I had repeatedly explained her about significant of
Study on Nutritional Problems in Preschool Aged Children of Kaski District of Nepal 
Acharya, $\mathrm{J}$ van Teijlingen, $\mathrm{E}$ Murphy, J Hind, $\mathrm{M}$

\author{
colostrum for new borne which I had learnt from FCHV Bahini few weeks \\ ago, even she did not agreed with me and I compelled to discard it".
}

FGD: Mother Group, Pokhara

\section{DISCUSSION}

Nepal has diverse scenery which makes various socio-cultural aspects such as culture, religion, caste /ethnicity, and language [13]. The majority of the people are Hindu. The official language is Nepali and there are more than 92 different languages spoken across the country. There are more than 103 different castes (ethnic groups) all over the country [75]. There is a strongly embedded caste system which describes the social stratification by ethnicity. Even though it is officially eliminated but there are social differences related to caste and ethnicity [9].

This research found that nearly $42 \%$ mothers have no or poor knowledge on sign and symptoms of undernunutrition. Most of the them reported that they are unaware that the children presenting the following signs and symptoms are correlated with undernunutrition: crying, irritating, quarrelling, not sleeping, diarrhoea \& vomiting, low weight, lean and thin, short in height and slow in growth, poor appetite, looking as weak health, mentally regarded, rough or dry skin.

The lack of knowledge on wellbeing and health safety along with nutritious food and health services uptake in Nepal include traditional/ spiritual supporters and their status in the society. The mis-beliefs are strongly embedded in the poor and underserved community as well as in some part of urban area because of migration due to ten year conflict in the country. The Spiritual and Traditional supporters or advocators usually are Hindu, as the proportion is $87 \%$ of the population [62]. In rural part of Nepal, many traditional beliefs still exist, for example, leprosy is believed to be caused by sin in one's past life or to be a curse from God [1].The poor community strongly trusts traditional/ spiritual healers and however they have first choice is spiritual/traditional healers in case of tiny health issues. The priest, illiterate household, spiritual/traditional healer, old parents have still high trust on mis-belief which is still influencing by them in the society.

Almost the whole of the Nepali society is using the traditional medicine as the first step of health care and they go to traditional or spiritual healers with any health problems [62] . One key problem is the poor decision making by family members in urban or rural areas due to the lack of recognition of complications of any ailments [40].However, there is a lack of knowledge on health care issues in Nepalese society.

This study has found that demographic determinants such as age of mother, level of education, age and gender of child, family type and size were found to be associated significantly with nutritional problems in 3-5 years old children of Kaski district [51],[59]. Present study revealed that majority of respondents (57\%) had more 
than six members living together. Similarly, $35 \%$ had less than six and nearly $8 \%$ households living with less than four family members. As the context of Nepalese society mainly in Hindu culture the family structure is called extended family that consisted by the immediate family structure which is involving of grandparents with close relatives such as aunts, uncles and cousins who all live together in the same family. This family structure might changes from immediate to extended household [4]. Big family size leads to poor nutrition status of children. The children from poor and disadvantaged group are more vulnerable of poor nutrition. This might be difference due to study period, health service delivery, locality of the study, socioeconomic characteristics, occupation and age. Most of the children taken to working places such as farming field, building construct site, and other house chores, by their parents if there is no anyone available to look after the small children at home.

Mainly the level of knowledge on nutritious food and poverty are the major barriers seen in the field of nutrition that are associated with food security, food prices, and income trends of households [2]. Poverty, caste, gender and social inequalities and conflict are regarded as secondary barriers for the nutritional problems in Nepal [21],[10],[11],[3]. The ten-year long conflict in Nepal has increasingly centralised systems, disrupt the development of rural areas and badly affected health services [22] and ultimate aims to migrate to secure place. Although the risks involved in lack of transport, high service cost, long distances, full trust on spiritual and traditional healers because they are easily available and affordable for poor people, insufficient health resources, and lack of capacity to treat serious problems at the nearby primary health care service centres. At the same time, the country is on the way to accomplish the MDGs 4 and 5 targets [23]. Similarly, child undernunutrition can also lead to poorer health and higher risk of mortality in later life. Many factors have been associated with poor nutrition. Mainly these include the magnitude of poverty as measured by socio economic status, availability of food and poor diet, practice of breastfeeding, the incidence of infectious and parasitic ailments, health care access, immunisation history, vitamin A supplementation, care during pregnancy, water supply and sanitation, health seeking behaviour, and demographic characteristics, including age and sex of child, mother's age and child spacing [54],[60],[70],[69].

P. Fieldhouse defines the custom and culture as "Minority groups, whether they be defined in social, cultural or ethnic terms may hold values which differ from those of the dominant culture and this is reflected in their beliefs, attitudes and practices related to food" [26].

The ethnic or traditional beliefs concerning to contamination of food and social values and norms in which rural women are not preferred because of their low rank have negative significances on the foods of women particularly by reducing their intake of desired, rich of micronutrient food such as meat items, dairy products and vegetables [28]. This type of traditional beliefs and manners could have a mostly negative influence on pregnant women given the intensified functional needs for various
Study on Nutritional Problems in Preschool Aged Children of Kaski District of Nepal 
Acharya, $\mathrm{J}$ van Teijlingen, E Murphy, J Hind, $\mathrm{M}$ micronutrients. Thus ethnic beliefs and practices that impact women's nutritional eating during pregnancy have significant insinuations for both micronutrients and macronutrient lacks among pregnant women in Nepal.

Beliefs about the 'hot or cold' quality of food and their effects, on the health of human, are likewise widespread in the world, and have a strong impact on eating manners during illness, pregnancy, and lactation and [27]. Most of the South Asian region, these body states are supposed to be principally sensitive to the hot or cold merits of food and depending on an individual's physical state, hot or cold foods are believed to have either a negative or positive effect on the human body [14]

Often, it has been recommended that the sense of women is in fact having a big baby will result in increased labour risk, among women with short build in the context of south Asian region [55].

In Iran, African regions, South Asia and even some European countries, pregnant women have been observed to reduce food intake during pregnancy, a behaviour generally referred to in the literature as easting down [31]. It is reported that the causes of eating down in South Asian contexts, where the behaviour is hypothetically general, were connected to fears that having a large baby could lead to more difficult deliveries. In Nichter (1983) revealed beliefs about food intake behaviour of pregnant women of India, that the food taken by pregnant women that stocks equal cosmos in the stomach as the fetus and women eaten less meal in order to give the baby space to thrice in the limited shared space [47].

The food beliefs In South Asian culture commonly associated with ancient Ayurveda as well as Hindu religion [29],[43]. According to food beliefs of Ayurveda, whole foods have been classified into hot and cold, are profoundly embedded in the epistemological grounds of many cultures and can provide a theoretical framework for expressing the complex of linkages between diet and health [8].Hot and Cold beliefs are held by many people in South Asian Region. This perception is believed to came from the ancient Hindu or Ayurveda and has been influential in medical practices [43]. This perception also practiced in Unani medical systems [61]. This beliefs system is complex and does not reflect that ideal by dominant Western Scientific medicine which generally prescribes to evidence based medicine and classifies food into groups representing the main micronutrient composition such as protein, fat, alcohol and carbohydrate [46]. Adherence to beliefs also tends to be stronger in the rural community of Nepal and among the disadvantaged and illiterate [26]. During these days food beliefs regarding hot and cold is vary between locality and ethnic groups as well as regions and countries. In general use of the hot and cold food categorise scheme avoid in the locality, through like general the use of the hot and cold food categorise scheme avoid in the community, though likely to differ between persons due to variances in understanding and economic capitals, may mean that conventional nutritional counselling is ineffective among those who follow this beliefs and reject scientific values, at least those in relation 
to food choice [26]. The rejection of recommendations therefore, may not be due to persons not wanting to make changes but somewhat the recommendations not being compatible with their beliefs so health workers would not to know lay ideologies and adapt their techniques accordingly [26]. According to Fieldhouse (1995) the social and human behaviours are influenced by a variety issues as well as surroundings and financial pressures which impact on food choices and physical activity.

\section{Beliefs about Breastfeeding and colostrum}

It has been observed that some women of the Nepalese communities, mainly from the rural locality and non-educated background, do not breastfeed on the day of child birth and even second day and it is common in South Asian region as well [18]. They stimulate their breasts and squeeze out the colostrum [6]. In terms of breastfeeding rates, it is high in Nepal when compared with breast feeding rate in England at six months and six weeks.

This study found that nearly $20 \%$ of the mothers explored negative perceptions such as mother become weak, ugly, breasts may shrink, get older in early life, may develop breast cancer, in regards to regular and excessive breastfeeding to children. Similarly $16 \%$ mothers had negative perceptions about feeding of colostrum such as it is forms pus, is toxic, dirty and smells bad. Hence they believe that colostrum needs to be squeezed out and should not be fed to the baby.

On the other hand, $71 \%$ of the community had positive perceptions about the feeding colostrum such as " it is good for the child's health,and it is a highly nutritious substance and compulsorily to be fed to the new born."

Malnutrition is a major contributor to the total global disease burden. More than one third of child deaths worldwide are attributed to undernutrition. Poverty is a central cause of under nutrition. As per the World Bank statistic (2015), Nepal's GDP per capita (US\$1,049/pa) is very low to fulfil the basic need of the households[77].

A key indicator of chronic undernunutrition is stunting - when children are too short for their age group compared to the WHO child growth standards. About 178 million children globally are stunted, resulting from not enough food, a vitamin- and mineral-poor diet, and disease[7], [67]. As growth slows down, brain development lags and stunted children learn poorly. Stunting rates among children are highest in Africa and Asia. In south-central Asia 41\% are affected [67].

Hidden hunger is a lack of essential vitamins and minerals in the diet, which are vital to boost immunity and healthy development. Vitamin A, zinc, iron and iodine deficiencies are primary public health concerns [73]. About 2 billion people are affected by iodine deficiencies worldwide; and vitamin $\mathrm{A}$ is associated with more than half a million deaths of under-five children globally each year [73], [81].
Study on Nutritional Problems in Preschool Aged Children of Kaski District of Nepal 
Acharya, $\mathrm{J}$ van Teijlingen, E Murphy, J Hind, $\mathrm{M}$
The rise in overweight and obesity worldwide is a major public health challenge. People of all ages and backgrounds face this type of malnutrition. As a consequence, rates of diabetes and other diet-related diseases are escalating, even in developing countries. In a few developing countries, up to $20 \%$ of children under-five are overweight[73].

Good nutrition during pregnancy ensures a healthier baby. WHO recommends exclusive breastfeeding for six months, introducing age-appropriate and safe complementary foods at six months, and continuing breastfeeding for up to two years or beyond[74]. About $20 \%$ of deaths among children under-five worldwide could be avoided if these feeding guidelines are followed. Appropriate feeding decreases rates of stunting and obesity and stimulates intellectual development in young children [78].

Observation during the interview period also included construction materials for the building of residents within the urban and rural area. In regards to use of construction materials of the houses, sources of safe drinking water and use of cooking fuels, sanitation, drinking water purification, ownership of land, family size, income of the household, were measured as a compilation indicator of household prosperity and assets [37]. However, in the context Nepalese society, poverty, education, sanitation and safe drinking water are associated with child under-nutrition. Educational status is included as a separate variable in analyses since it is not a component of the wealth index. The population wealth quintiles and education offer a measure of socioeconomic status.

There are several impacts of food selections with age, gender, and social class along with ethnicity, attitudes, culture, and composition of household and deeply enrooted beliefs. In terms of inequalities, the people that belong to educated and advanced socioeconomic groups tend to have good diet. This may be due to being capable to well conceptualize the association between health and nutrition [16] but the reality that the group with higher incomes are capable to pay for nutritionally balanced and high quality foods. Similarly low income groups could not afford food choice which included fruits, meat items, and green vegetables [16]. Nutritious foods such as meat items, dairy products, fruits and green vegetables often cost more than low quality or cheap foods. The cheap or low quality foods are lower in important nutrients [30]. Poor income groups may also be limited in their capacity to purchase nutritious diets due to insufficient access both physically and financially. Only the basic necessities were purchased and the social variables religion had one of the most powerful roles in the selection of which diet to be followed [24].

\section{CONCLUSION/RECOMMENDATION}

Knowledge and attitudes towards nutritious food of rural and urban mothers are still poor in both societies. Beliefs about food practices are still strongly embedded in Nepal. 
Urban mothers had better food recommendation, whereas rural mothers experienced huge barriers. Meat, fish, eggs and dairy products are not provided to children due to cultural influences. Mothers from both communities have high faith in spiritual healers. Child feeding practices in the community is very poor compare to developed countries. Approximately $20 \%$ mothers still believed that feeding of nutritious foods during the illness period caused harm. The research found that community people have strong hold on the beliefs about healthy foods within the community such as impure and pure, cold, hot and neutral, harmful or beneficial or curative. Following beliefs is strongly embedded in the society that "if a pregnant woman eats more she will have bigger baby which can cause problem during labour". Therefore, pregnant woman are not allowed to take nutritious food in the rural part of Nepal. This study would endorse community based nutrition programme should be established and integrated with public health network at community level. Nutrition education programmes should be provided, using various methods by mobilising local level stakeholders, focusing on knowledge, attitudes and beliefs about nutritious food, to community people targeting to poor, disadvantaged and vulnerable communities which indicated in this study mainly poor knowledge, enrooted traditional beliefs and inappropriate attitudes of parents about nutritious food.

\section{ACKNOWLEDGEMENTS}

The authors of this study would like to thank Global Supplementary Grant Programme/ Open Society Foundation, Europe; Sight and Life, Switzerland; Post Graduate Research Development Fund of Bournemouth University and Santander Bank for generous support for this study and Nepal Health Research Council for the ethical approval.

\section{REFERENCES}

[1] Acharya, J.R. (2012). The Barriers to uptake of eye care services for leprosy patients in Nepal. An article published in Participation (National Journal), A Nepalese Journal of Participatory Development, 59-69. Available at: www.nepan.org.np/gallery/publication/ PARTICIPATION-13.pdf accessed 15 Jan. 2015

[2] Acharya,M. And Bennett, L.(1981). The rural women of Nepal: An aggregate analysis and summary of 8 village studies, Kathmandu: Centre for Economic Development and Administration, Tribhuvan University.

[3] Adhikari, J. (2010). Food insecurity, conflict and livehood threats in Nepal in Livelihood Insecurity and Social Conflict in Nepal (eds.Upreti,BR and MÛller-BÓker,U). South Asia Regional Coordination Office; Swiss National Centre of Competence in Research (NCCR) North-South; Kathmandu.

[4] Andersen, ML., and Taylor, HF.(2007). The extended family may live together for many reasons, such as to help raise children, support for an ill relative, or help with financial problems. Sociology: Understanding a diverse society. p. 396 ISBN 0-495-00742-0.

[5] Asres, G., and Eidelman, A.I.(2011). Nutritional assessment of Ethiopian Beta-Israel children: a cross-sectional survey. Breastfeed Med 6: 171-176.

http://dx.doi.org/10.1089/bfm.2011.0016. PMid:21770732
Study on Nutritional Problems in Preschool Aged Children of Kaski District of Nepal

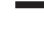


Acharya, $\mathrm{J}$ van Teijlingen, E

Murphy, J

Hind, $M$
[6] Bandyopadhyay, M. (2009). Impact of ritual pollution on lactation and breastfeeding practices in rural West Bengal, India. International Breastfeeding Journal 4, 2. http:// www.internationalbreastfeedingjournal.com/content/4/1/2 accessed Dec.14, 2014. http://dx.doi.org/10.1186/1746-4358-4-2. PMid:19323839 PMCid:PMC2667394

[7] Babatunde, R.O., Olagunju, F.I., Fakayode ,S.B., and Sola-Ojo, F.E.(2011). Prevalence and determinants of Malnutrition among Under-five Children of Farming Households in Kwara State, Nigeria. Journal of Agricultural Science 3: 173-181. http://dx.doi.org/10.5539/jas.v3n3p173

[8] Beardsworth, A., and Keil, T. (1997) .Sociology on the menu: an invitation to the study of food and society Routledge, London.

[9] Bennett, L. (2005).Gender, Caste, and Ethnic Exclusion in Nepal: Following the Policy Process from Analysis to Action. Paper presented at the Conference New Frontiers of Social Policy: Development in a Globalizing World, Arusha, Tanzania.

[10] Bishwakarma, R.(2009). Social Inequalities in Child Nutrition in Nepal. Word Bank Internship Project Paper. Washington,D.C.

[11] Bishwakarma, R., and Vanneman, R.(2008). Caste, Gender, and Location effect on Child Stunting in Nepal. Paper published in American Sociological Association Meetings, Boston. October 2008.

[12] Bouis, H. and Hunt,J. (1999). Linking food and nutrition security: Past lessons and future opportunities. Asian Development Review 17 (1-2): 168-213.

[13] Bhattachan, K., Sunar, T. B., Bhattchan,Y. K. (2009). Caste-based Discrimination in Nepal. Working Paper Series. (3). Indian Institute of Dalit Studies. New Delhi.

http://dx.doi.org/10.1596/1813-9450-4866

[14] Bryant, C.A., DeWal,KM., Courtney, A., and Schwartz, J. (2003).The Cultural Feast: An Introduction to Food and Society, 2nd Ed. Belmont, CA: Thomson Wadsworth.

[15] Caulfield L.E, de Onis, M., Blössner, M., and Black, R.E.(2004). Undernutrition as an underlying cause of child deaths associated with diarrhea, pneumonia, malaria, and measles. Am J Clin Nutr 80: 193-198. PMid:15213048

[16] Cox, D.N. \& Anderson, A.S. (2004). "Food Choice," in Public Health Nutrition, Gibney MJ et al., eds., Blackwell Science, Oxford, pp. 146-166.

[17] Christakis, G. (1973). Nutritional assessment in health problems. Am. J. Public Health, 63(suppl): 1. PMid:4768543

[18] Darmstadt, G.L., Syed, U., Patel, Z., Kabir, N. (2006). Review of domiciliary newborncare practices in Bangladesh. Journal of Health, Population, and Nutrition 24(4), 380-393. PMid:17591335 PMCid:PMC3001142

[19] de Onis, M.et al. (2004). Estimates of global prevalence of childhood underweight in 1990 and 2015. JAMA 291: 2600-2606. http://dx.doi.org/10.1001/jama.291.21.2600

PMid:15173151

[20] de Onis, M., Frongillo, E.A., and Blössner, M.(2000). Is malnutrition declining? An analysis of changes in levels of child malnutrition since 1980. Bull World Health Organ 78: 1222-1233. PMid:11100617 PMCid:PMC2560621

[21] Deolalikar, A.B. (2005). Poverty and Child malnutrition in Bangladesh, Journal of Developing Societies: 21 (1-2) : 55-9. http://dx.doi.org/10.1177/0169796X05053067 
[22] Devkota, B., and van Teijlingen, E. (2010). Understanding effects of armed conflict on health outcomes: the case of Nepal. Conflict \& Health 4 (20) www.conflictandhealth.com/ content /4/1/20. http://dx.doi.org/10.1186/1752-1505-4-20.

PMid:21122098 PMCid:PMC3003631

[23] DFID. (2009). Nepal: maternal mortality and Morbidity Study, London, see: www.dfid. gov.uk/Documents/publications/nepal-maternal-mortality.pdf

[24] Dindyal, S., \& Dindyal, S. (2004). "How Personal Factors, Including Culture And Ethnicity, Affect The Choices And Selection Of Food We Make", The Internet Journal of Third World Medicine, 1, 2.

[25] Edris, M.(2006). Assessment of nutritional status of preschool children of Gumbrit, Ethiop J Health Dev 21: 125-129.

[26] Fieldhouse, P. (1995). Food and Nutrition: Customs and culture., Second edn, Chapman \& Hall, London. http://dx.doi.org/10.1007/978-1-4899-3256-3. PMid:7733023

[27] Ferro-Luzzi,G.(1980). Food avoidances during the pueriperium and lactation in Tamilnad. In: J.K.R.Robson (Ed.), Food, Ecology and Culture, London: Gordon \& Breach Science Publishers, pp.109-117.

[28] Gittelsohn, J. Thapa, M. and Landman,L.T.(1997). Cultural factors, caloric intake and micronutrient sufficiency in rural Nepali households. Social Science \& Medicine, 44, 1739-1749. http://dx.doi.org/10.1016/S0277-9536(96)00375-9

[29] Hill,S.E.(1990). More Than Rice and Peas: Guidelines to improve food provision for Black and Ethnic Minorities in Britian, The Food Commission, London. Journal of Current Research 2: 103-108.

[30] James, P., Nelson, M., Ralph, A., and Leather, S. (1997). "The contribution of nutrition to inequalities in health", British Medical Journal, 314, 24 May, pp. 1545-1549.

http://dx.doi.org/10.1136/bmj.314.7093.1545. PMid:9183207 PMCid:PMC2126753

[31] Karim, R et al. (2003). Determinants of food consumption during pregnancy in rural Bangladesh: examination of evaluative data from the Bangladesh Integrated Nutrition Project. Tufts University. Available from http://nutrition.tufts.edu/pdf/publications/fpan/ wp11-food_consumption.pdf accessed Feb.17,2015.

[32] Khongsdier, R., and Mukherjee,N.(2003). Effects of heterosis on growth in height and itssegments: a cross-sectional study of the Khasi girls in Northeast India. Ann HumBiol. 2003 Sep-Oct; 30(5): 605-21. http://dx.doi.org/10.1080/03014460310001592669.

PMid:12959901

[33] Kwena, A.M., et al.(2003). Prevalence and severity of malnutrition in pre-school children in a rural area of western Kenya. Am J Trop Med Hyg 68: 94-99. PMid:12749491

[34] Reed, B.A., Habicht, J.P. and Niameogo, C.(1996). The effects of maternal education on child nutritional status depend on socio-environmental conditions. Int J Epidemiol 25: 585-592. http://dx.doi.org/10.1093/ije/25.3.585. PMid:8671560

[35] Rocherson,Y. (1988). The Asian Mother and Baby Campaign: The Construction of Ethnic Minorities' Health Needs. Critical Social Policy 8, 4-23.

http://dx.doi.org/10.1177/026101838800802201

[36] Rome Declaration on Nutrition. (2014). WHY IT MATTERS \& WHAT CAN BE DONE; Second International Conference on Nutrition (ICN2), 19-21, November
Study on Nutritional Problems in Preschool Aged Children of Kaski District of Nepal 
Acharya, $\mathrm{J}$ van Teijlingen, E Murphy, $\mathrm{J}$ Hind, $M$
[37] Rustein, SO., and Johnson, K.(2004). The DHS wealth index: DHS comparative reports no 6. Calverton, MD: ORC Macro.

[38] Malla Pradhan,S.(2000). Property Rights of Nepalese Women. FES Nepal. Available at http://www.nepaldemocracy.org/gender/property_rights.htm. Assessed on Jan., 2015

[39] Merrill, W.(1984). Report of Workshop on income and Nutrition effects of increasing commercialization of semi-subsistence Agriculture. Air lie House Virginia. December 1984: 3-5.

[40] Moestue, J., and Huttly,S.(2008). Adult Education and Child Nutrition: The Role of Family and Community, Journal of Epidemiology and Community Health, 62:153-159. http://dx.doi.org/10.1136/jech.2006.058578. PMid:18192604

[41] Mulugeta, A et al. (2005). Factors Contributing to Child Malnutrition in Tigray, Northern Ethiopia. PMCid:PMC2715321

[42] Müller, O., and Krawinkel, M.(2005). Malnutrition and health in developing countries. CMAJ 173: 279-286. http://dx.doi.org/10.1503/cmaj.050342.

PMid:16076825 PMCid:PMC1180662

[43] Nagpal, N. (2003). "Health Matters: Coping Indigenously", Nursing Journal of India, 94, 4, pp. 78-80. PMid:15315197

[44] NDHS.(2011). Nepal Demographic Health Survey, New ERA under the aegis of the Ministry of Health and Population. ICF International provided technical assistance for the survey through the USAID Nepal.

[45] NDHS. (2006). Nepal Demographic Health Survey, CBS, Journal of Current Research 2: 103-108.

[46] Nichter, M. (1989). Anthropology and International Health: South Asian Case Studies Kluwer Academic Publishers, London. http://dx.doi.org/10.1007/978-94-009-2231-0

[47] Nichter,M., Nichter,M.(1983).The ethnophysiology and fold dietetics of pregnacny. Human organization, 42, 234-246.

[48] Odent, PL. G. (2010). Early infant feeding and neonatal survival in Nepal: Breastfeeding, colostrum and discarding of the first milk. University College London, U.K.

[49] Ola, E., Ahmed, and Mofida, Y., et al. (2011). Nutritional status of the children under age of five in a decertified area of Sudan - Alrawakeeb valley. International

[50] Otgonjargal, D et al. (2012). Nutritional status of under- five children in Mongolia. Journal of Medicine and Medical Sciences 3: 341-349. 15.

[51] Pandey,S et al.(2010). Determinants of infant and young child feeding practices of Nepal: Secondary data analysis of DHS 2006. Food and Nutrition Bulletin; 31(2):334-51.

PMid:20707237

[52] Riordan, J. and Hoover, K. (2005). Perinatal and Intrapartum Care. In Riordan J (ed) Breastfeeding and Human Lactation. Jones and Bartlett: London. Pp. 185-217.

[53] Rome Declaration.(2014). Rome Declaration on Nutrition, Why it matters \& What can be done, Second Internal Conference on Nutrition (ICN2), November, 17-21.

[54] Ross, D.A et al.(1995). Child morbidity and mortality following vitamin A supplementation in Ghana: Time since dosing, number of doses, and time of year. American Journal of Public Health 85, 1246-1251. http://dx.doi.org/10.2105/AJPH.85.9.1246

PMid:7661232 PMCid:PMC1615567 
[55] Rush, D.(2000). Nutrition and maternal mortality in the developing world. American Journal of Clinical Nutrition, 72 (suppl), 212S-240S. PMid:10871588

[56] Sapkota,V.P., and Gurung, C.K.(2009). Prevalence and Predictors of Underweight, Stunting and Wasting in Under-Five Children. Nepal Health Res Counc 7: 120126.

[57] Senbanjo, I.O., Adeodu, O.O., and Adejuyigbe, E.A.(2009). Influence of socio-economic factors on nutritional status of children in a rural community of Osun State, Nigeria.

[58] Siddiqui, N.A., Haque, N., and Goni, M.A.(2011).Malnutrition of Under-Five Children: Evidence from Bangladesh. Asian Journal of Medical Sciences 2: 113-118. 14.

[59] Subba, S.H. et al. (2007). Infant feeding practices of mothers in an Urban areas in Nepal, Kathmandu University Medical Journal; 5, 1, 42-47.

[60] Schoenbaum, M., Tulchinsky, T.H., and Abed, Y.(1995). Gender differences in nutritional status and feeding patterns among infants in the Gaza Strip. American Journal of Public Health 85, 965-969. http://dx.doi.org/10.2105/AJPH.85.7.965.

PMid:7604921 PMCid:PMC1615541

[61] Storer, J. (1977). "Hot and Cold food beliefs in an Indian Community and their significance", Journal of Human Nutrition, 31, 1, pp 33-40. PMid:326951

[62] Tamang, A., and Broom, A.(2010). The practice and meanings of spiritual healing in Nepal. South Asian History and Culture, 1, 2:328 - 340.

http://dx.doi.org/10.1080/19472491003593084

[63] Tesfaye, M.(2009). Bayesian approach to identify predictors of children Nutritional status in Ethiopia.

[64] Tierney, L.M., McPhee,S.J., and Papadakis, M.A.(2004). Assessment of nutritional status: Current Medical Diagnosis and Treatment. Lange Medical Books/McGrawHill, New York. pp 1210-3.

[65] UN/SCN. (2010). 6th report on the world nutrition situation: progress in nutrition. Geneva: Administrative Committee on Coordination-Standing Committee on Nutrition, United Nations.

[66] UNICEF.(2014). UNICEF-WHO-The World Bank Joint Child Malnutrition Estimates, September. Available at http://www.who.int/nutgrowthdb/estimate accessed on November, 2014

[67] UNICEF REPORT.(2005).The State of the World's Children; A UNICEF REPORT: Childhood under threat.

[68] USAID.(2007). Nutritional status and its determinants in southern Sudan.

[69] Vijayaraghavan, $\mathrm{K}$ et al.(1990). Effect of massive dose vitamin A on morbidity and mortality in Indian children. Lancet 336, 1342-1345.

http://dx.doi.org/10.1016/0140-6736(90)92895-O

[70] Vella,V.atel.(1992).Determinants of child nutrition and mortality in north-west Uganda. Bulletin of the World Health Organization 70, 637-643. PMid:1464151 PMCid: PMC2393364

[71] WFP.2013. Available at http://www.wfp.org/countries/nepal/overview accessed on 17 January, 2015

[72] Willett,W.C. and Stampfer, M.J. (2013). Current evidence on healthy eating. Annual Review of Public Health; 34, 77-95. http://dx.doi.org/10.1146/annurev-publhealth-031811-124646 PMid:23297654
Study on Nutritional Problems in Preschool Aged Children of Kaski District of Nepal 
Acharya, J van Teijlingen, E Murphy, J Hind, $\mathrm{M}$
[73] WHO. (2014). UNICEF-WHO-The World Bank Joint Child Malnutrition Estimates, September. Available at http://www.who.int/nutgrowthdb/estimate accessed on November, 2014

[74] WHO. (2014a). World Health Organization, Nutrition: Exclusive breast feeding http:// www.who.int/nutrition/topics/exclusive_breastfeeding/en/ Accessed 15 January, 2015.

[75] WHO.(2006). The country co-operation strategy, 2006 - 11. Available at http://www.who. int/countryfocus/cooperation_strategy/ccs_npl_en.pdf, Accessed on 17 Jan., 2015

[76] WHO.(1989). WHO EMRO Technical Publication No 13. Guidelines for the development of a food and nutrition surveillance system for the countries in the Eastern Mediterranean Region Based on the deliberations of a WHO/FAO Inter Country Meeting on Nutrition Surveillance Islamabad, Pakistan, October 1988.

[77] World Bank .(2015). Global Economic Prospects: A World Bank Group Flagship Report, South Asia; Chapter 2, Pg. 89-100 Available at http://www.worldbank.org/content/dam/ Worldbank/GEP/GEP2015a/pdfs/GEP15a_web_full.pdf Accessed on 24th January, 2015.

[78] World Bank.(2014). UNICEF-WHO-The World Bank Joint Child Malnutrition Estimates, September. Available at http://www.who.int/nutgrowthdb/estimate accessed on November, 2014

[79] World Bank.(2008). Nepal Country Overview 2008, Available at http://www.worldbank.org.np/WBSITE/EXTERNAL/

[80] Yimer, G.(2000). Malnutrition among children in southern Ethiopia: Levels and risk factors. Ethiopian Journal of Health Development 14: 283-292. http://dx.doi.org/10.4314/ejhd.v14i3.9901

[81] Zewdu, S.(2012). Magnitude and Factors Associated with Malnutrition of Children Under Five Years of Age in Rural Kebeles of Haramaya, Ethiopia. Harar Bulletin of Health Sciences 4: 221-232. 